\title{
Motivational orientations to mindfulness and wellbeing
}

\author{
Hanna Suh
}

\begin{abstract}
Adopting self-determination theory as a guiding framework, this cross-sectional study examined how motivational orientations (perfectionistic strivings, perfectionistic concerns) relate to mindfulness, core self-evaluation, and outcomes of life satisfaction, depression, and anxiety. A total of 273 college students responded to measures of perfectionism, mindfulness, core self-evaluation, life satisfaction, depression, and anxiety. Results supported that mindfulness and core self-evaluation sequentially mediated the associations between perfectionistic concerns and outcomes, but the hypothesized serial mediation model was not supported for perfectionistic strivings. Findings suggest that decentering with awareness may build positive self-evaluation and thus mitigate the effects of perfectionistic concerns on life satisfaction, depression, and anxiety. On the other hand, not mindfulness but positive self-evaluation alone functions as a binder in the association between perfectionistic strivings and outcome variables. This study concludes that perfectionistic strivings and perfectionistic concerns, each positioned to reflect autonomous motivational orientations and controlled motivational orientations, relate to wellbeing with or without the role of mindfulness.
\end{abstract}

Keywords: Mindfulness $\cdot$ Perfectionism $\cdot$ Motivational orientations $\cdot$ Wellbeing

\section{Introduction}

Amidst the surge in interest regarding mindfulness, one line of research focuses on understanding possible mechanisms through which the effects of mindfulness lead to wellbeing (e.g., Sauer, Walach, \& Kolhs, 2011; Schutte \& Malouff, 2011). The definition of mindfulness is met with little consensus, but Ivtzan and Hart (2016) provide a useful way of delineating different historical and theoretical backgrounds upon which mindfulness is defined. Specifically, Ivtzan and Hart (2016) note that the Western definition of mindfulness from Langer and colleagues investigates mindfulness as a "cognitive mode" grounded in a person's disposition (Langer, 1994). According to this definition, mindfulness refers to one selfregulating consciousness by directing attention to an external stimuli and engaging with the external stimuli in a creative way. In other words, this definition of mindfulness emphasizes paying effortful attention to an external stimulus (e.g., experiences) and also emphasizes a new engagement pattern. On the other hand, the Eastern definition of mindfulness is derived from 
meditative practices guiding Kabat-Zinn's definition that emphasizes awareness, attention, and remembering. This definition emphasizes having metacognitive skills with acceptance as an indicator of presence of mindfulness. Ivtzan and Hart (2016) summarize the difference between these two definitions of mindfulness by stating that:

“The Western approach describes mindfulness as an effortful attentive-creative mode of awareness, where one engages closely with an external experience of environment. The Eastern approach, on the other hand, depicts mindfulness as a metacognitive mode, in which one attends to internal or external experiences in a manner that paradoxically involves an intimate engagement with the experience, and at the same time an ability to disidentify oneself from the cognitions and emotions that the experiences provokes" ( $p$. 20).

Clarifying the definition of mindfulness is important because it has implications for understanding its pathways to wellbeing, although these two definitions of mindfulness appear to have been used interchangeably in the literature. Theoretically, the associations between mindfulness and wellbeing can be explained within the framework of self-determination theory (SDT; Brown \& Ryan, 2003; Ryan \& Deci, 2017). SDT posits that mindfulness allows for "clarity and freshness that can liberate people from automatic responses and foster more selfendorsed behavior" (p. 271, Ryan \& Deci, 2017). In other words, mindfulness facilitates a more thorough observation of internal and external experiences by creating a "space" for reflective and autonomous regulation of actions. With high mindfulness, individuals act more autonomously, which then affects emotional wellbeing (Brown \& Ryan, 2003). Brown and Ryan (2003) indicate this process as a "healthy regulation" in which a person is focused on abiding by their values, needs, and true demands of situations through mindfulness. Such healthy regulation is linked to autonomous functioning (Weinstein \& Ryan, 2011). Studies conducted on mindfulness within the framework of SDT appears to adhere to the Eastern definition of mindfulness, although mindfulness measures that reflect the Western definition of mindfulness (e.g., Mindfulness Attention and Awareness Scale; MAAS) also seem to have been used in these studies (e.g., Brown \& Ryan, 2003). Indeed, the MAAS was developed to reflect the Eastern definition of mindfulness. Notwithstanding some theoretical and conceptual differences, this study chose to use the MAAS to reflect mindfulness, given its original usage within the SDT framework.

Consistent with theoretical propositions, empirical findings show positive links between mindfulness and wellbeing. Numerous studies have now established links between mindfulness and wellbeing (e.g., for a review, see Khoury et al., 2013). Studies that examine mechanisms through which mindfulness exerts its effects on wellbeing appear to focus on selfreferent processing (e.g., self-esteem, self-efficacy). For example, mindfulness is associated with self-esteem (Brown \& Ryan, 2003; Thompson \& Waltz, 2008), and some find that mindfulness influences self-esteem (Pepping, O’Donovan, \& Davis, 2013). In explaining the link from mindfulness to self-esteem, Pepping, O'Donovan, and Davis (2013) explained that being nonreactive, aware, and non-judgmental toward arising negative thoughts about the self prevents negative evaluations becoming a true reality. A construct that encompasses both self-esteem and self-efficacy, along with two other components (emotional stability, locus of control), is core self-evaluation. Defined as having positive view of oneself and confidence in one's own 
abilities, core self-evaluation is linked to wellbeing (Judge, Erez, Bono, \& Thoresen, 2003). One way in which a high core self-evaluation level allows experiencing high satisfaction in life is by letting individuals set goals that are self-concordant (Judge, Bono, Erez, \& Locke, 2005), perhaps clarified through greater mindfulness. Extended to include outcome variables reflective of wellbeing, Kong, Wang, and Zhao (2014) found that the extent to which one positively evaluates oneself fully mediates the association between trait mindfulness and life satisfaction.

At the same time, individual differences in the propensity towards healthy and unhealthy regulation will likely influence mindfulness, core self-evaluation, and wellbeing. One factor that is relevant is motivational causality orientations. Causality orientations theory (COT) is one of six mini-theories within SDT and outlines individual differences in motivational styles (Ryan \& Deci, 2017). Specifically, causality orientations refer to "motivational sets or characteristic ways of perceiving and organizing motivationally relevant perception and information" (p. 217, Ryan \& Deci, 2017) and indicate that there are individual differences in orienting towards the environment (e.g., social context) and individuals' own motivations (e.g., personal needs, values). In the orientation towards contexts, autonomous motivational orientation indicates taking contexts as a source of information and being directed by choice and self-determination. Controlled motivational orientation indicates interpreting the environment as controlling and being directed by external rewards and social pressures (Ryan \& Deci, 2017). In orienting to individuals' own motivations, autonomous motivational orientation reflects the degree to which people tend to be attuned to inner needs, interests, and values, and the controlled motivational orientation taps onto the degree to which people tend to refer to external cues and controls in the environment to guide their behaviors. Accordingly, individuals functioning upon autonomous motivational orientation are inclined towards using inner anchors (e.g., values, needs) as guidance towards behaviors. On the other hand, those who function upon controlled motivational orientation are sensitive to, and their behaviors are largely dictated by, "external demands, rewards, threats and self-esteem contingencies" (p. 665, Ryan \& Deci, 2008). These motivational causality orientations are linked to how individuals self-regulate. Following the organismic integration theory (OIT), another one of six minitheories of SDT, high autonomous motivational orientation is associated with identified and integrated styles of regulation, while high controlled motivational orientation is associated with preoccupation with external judgments and contingencies, which then regulate behaviors (e.g., introjected regulation). A recent meta-analysis by Howard, Gagné, and Bureau (2017) again concluded that motivation falls along the continuum of self-determination, wherein autonomous motivational orientation is reflective of integrated or identified regulations, while controlled motivational orientation is reflective of introjected regulation and external regulation.

Not surprisingly, motivational orientations differentially influence wellbeing. For example, Gillet, Lafrenière, Vallerand, Huart, and Fouquereau (2012) found that autonomous motivational orientation was positively correlated with positive affect, whereas controlled motivational orientation was negatively associated with affect among university students. Similarly, in an experimental study with college students, Nix, Ryan, Manly and Deci (1999) found that individuals assigned to an autonomous motivation condition (self-directed 
condition) showed a vitality level that was maintained; however, those who were assigned to the controlled motivation condition (other-directed condition) showed a drop in vitality level. Interestingly, there was no difference between conditions for happiness levels. Expanding to employee wellbeing in work settings, Slemp, Kern, Patrick, and Ryan (2018) found through their meta-analysis that autonomous work motivation is strongly and positively correlated with leader autonomy support (supervisor behaviors that facilitate self-determined motivation in employees) but leader autonomy support was uncorrelated with controlled work motivation. Leadership autonomy support was, in turn, associated with hedonic and eudaimonic wellbeing respectively ( $\rho=.46$ [CI .39, .53], $\rho=.40$ [CI .29, .52]). In sum, results that show the linkages of autonomous motivational orientations and controlled motivational orientations to wellbeing seem to be mixed, and this inconsistency could be clarified through exploring perhaps divergent pathways between motivational orientations and wellbeing.

The relations between motivational orientations and mindfulness is also unclear. Two plausible relations may exist. First, motivational orientations may facilitate mindfulness. If one is driven by self-concordant values and needs (i.e., autonomous orientation), this may lead to clearer attention and awareness of present moment experiences, ultimately leading to positive self-evaluation and wellbeing. Similarly, if one is driven by external demands, rewards, and self-contingencies (i.e., controlled orientation), such preoccupation may also thwart being able to pay attention to present moment experiences because meeting the demands and contingencies are of utmost priority. Such preoccupation can then negatively influence one's self-evaluation and wellbeing. Second, mindfulness may influence motivational orientations. For instance, heightened awareness may allow one to orient towards certain motivations, needs, and values.

Based on theoretical propositions of SDT and empirical findings, this study proposes that motivational orientations should be considered when examining the link between mindfulness and wellbeing. Specifically, this study posits that mindfulness and core selfevaluation will sequentially mediate the association between motivational orientations and wellbeing. This proposition is informed by Brown and Ryan (2003), as they note:

"The effect of mindfulness lies not necessarily in creating psychological experiences ... but in allowing for choicefulness in whether to endorse or veto the directives that consciousness brings to awareness" (p. 118).

In other words, mindfulness may function as a carrier to an already established tendency toward self-regulation, guided by autonomous or controlled motivations.

According to Olesen (2011), motivational orientations can be conceived as characteristic adaptations, following the delineation proposed by McAdams and Pals (2006). Perfectionism is a multidimensional personality disposition that is relatively stable over time and distinguishable from dispositional personality traits (Rice, Ashby, \& Slaney, 2007; Stoeber \& Otto, 2006) that may reflect distinctive motivational orientations. Composed of two dimensions, perfectionistic strivings refer to setting high performance expectations while not experiencing discrepancy as to meeting such self-set expectations, whereas perfectionistic concerns refer to similarly setting high bars for one's performance while also constantly feeling inadequate at meeting such standards (Stoeber \& Otto, 2006). Bolstering this contention, Stoeber, Damian and Madigan (2018) recently argued that different motivational qualities may characterize 
perfectionistic strivings and perfectionistic concerns. Specifically, perfectionistic strivings generally showed positive relations with autonomous motivation (e.g., Harvey et al., 2015), whereas perfectionistic concerns primarily showed positive relations with controlled motivation (e.g., Miquelon, Vallerand, Grouzet, \& Cardinal, 2005). The adaptiveness and maladaptiveness of perfectionistic strivings and perfectionistic concerns have largely been witnessed through their associations with criterion variables, and results appear rather mixed. Although perfectionistic strivings are often considered an "adaptive/healthy" component of perfectionism, and perfectionistic concerns are often referred to as a "maladaptive/unhealthy" aspect of perfectionism (e.g., Dunkley, Mandel, \& Ma, 2014), a growing number of studies finds both dimensions of perfectionism as risk factors to psychological distress (Smith et al., 2016; Smith et al., 2017). Following the adaptive and maladaptive qualities and implications of perfectionistic strivings and perfectionistic concerns may or may not mirror the generally adaptive or maladaptive nature of and implications of autonomous and controlled motivations.

Perfectionistic strivings and perfectionistic concerns are associated with mindfulness and core self-evaluation. Across studies, perfectionistic strivings were either not significantly associated or significantly negatively associated with mindfulness $(r=-.27, p<.01)$, whereas perfectionistic concerns were strongly negatively associated with mindfulness ( $r$ s ranged from .47 to -.58 , all $p s<.01$ ) (Argus \& Thompson, 2007; Short \& Mazmanian, 2013; Wimberley, Mintz, \& Suh, 2016). The findings on the association with mindfulness appear rather inconsistent for perfectionistic strivings, but consistent for perfectionistic concerns. The association between perfectionism and core self-evaluation does not appear to be assessed, but given that core selfevaluation is reflective of self-esteem, self-efficacy, neuroticism, and locus of control (Judge et al., 2003), findings that examined the associations between perfectionism and self-esteem (selfefficacy) can suggest directionality of associations (e.g., Grzegorek, Slaney, Franze, \& Rice, 2004; Stoeber, Hutchfield, \& Wood, 2008).

\section{The present study}

Extending Kong et al. (2014) in two ways, this study first considers the role of a relevant yet unexamined covariate of motivational orientations (perfectionistic strivings, perfectionistic concerns) in the associations between mindfulness, core self-evaluation, and life satisfaction. Second, this study expands outcome variables of interest by including depression and anxiety as indicators of psychological distress. Serial mediation models in which mindfulness $\left(\mathrm{M}_{1}\right)$ and self-evaluation $\left(M_{2}\right)$ mediate the relation between perfectionism $(X)$ and outcomes $(Y)$ were tested. Serial multiple mediation models were run with bootstrapped indirect effects to test the following hypotheses:

$\mathrm{H}_{1 \mathrm{a}}\left(\mathrm{H}_{1 \mathrm{~b}}, \mathrm{H}_{1 \mathrm{c}}\right)$ : Perfectionistic strivings will be indirectly associated with life satisfaction (depression, anxiety), serially mediated by mindfulness and core self-evaluation.

$\mathrm{H}_{2 \mathrm{a}}\left(\mathrm{H}_{2 b}, \mathrm{H}_{2 c}\right)$ : Perfectionistic concerns will be indirectly associated with life satisfaction (depression, anxiety), serially mediated by mindfulness and core self-evaluation.

\section{Method}

\subsection{Participants and Procedure}


A total of 273 college students (211 female, 58 male, 1 transgender, and 1 declined to answer, 2 did not report) from a large public university participated. Participants were recruited from an undergraduate psychology research participant pool and several psychology courses, in exchange for research credit or extra credit. For extra credit, recruitment advertisement emails were sent to course instructors for distribution consideration. Initially, a total of 303 individuals logged onto the survey link; one indicated "disagree" at the informed consent stage, 26 agreed at the informed consent stage but did not proceed further, and three did not complete the survey and thus were excluded. Full final participant demographic information appears in Table 1. Questionnaires were presented online in a random order, using an online software, Qualtrics. The study took approximately 30 minutes to complete and was approved by the university institutional review board. Participants were recruited over two school semesters (spring and summer semesters of 2014), within approximately 7 months.

Table 1. Sample characteristics $(n=273)$

\begin{tabular}{ll}
\hline Age & Mean $=19.56(S D=2.72)$ \\
\hline Gender & Female $(n=211)$ \\
& Male $(n=58)$ \\
& Transgender $(n=1)$ \\
& Declined to answer $(n=1)$ \\
& Did not report $(n=2)$ \\
\hline Race/ethnicity & White or European American $(56.4 \%)$ \\
& Asian or Asian American $(14.3 \%)$ \\
& Hispanic/Latino/a (12.8\%) \\
& Black or African-American $(7.7 \%)$ \\
& Multicultural (3.7\%) \\
& Native American $(0.7 \%)$ \\
& Pacific Islander $(0.4 \%)$ \\
& Other (3.3\%) \\
& Did not report $(0.7 \%)$ \\
& First-year students (42.9\%) \\
& Sophomore $(25.6 \%)$ \\
& Junior (19.0\%) \\
Academic classification & Senior (10.6\%) \\
& Did not report $(0.4 \%)$ \\
\hline
\end{tabular}

\subsection{Measures}

Perfectionism. The Almost Perfect Scale-Revised (APS-R; Slaney et al., 2001) was used to assess perfectionistic strivings (seven items) and perfectionistic concerns (12 items). Sample items include, "I have high expectations for myself," and "I often feel frustrated because I can't meet my goals," for perfectionistic strivings and perfectionistic concerns respectively. Participants responded to a 7 -point scale $(1=$ strongly disagree, 7 = strongly agree $)$, with higher scores indicating greater perfectionistic tendencies. Internal consistency was sound for perfectionistic strivings (.82) and perfectionistic concerns (.92) among college students (Grzegorek et al., 2004), 
and validity was evidenced (Rice \& Ashby, 2007). Internal consistency was 92 for perfectionistic strivings and .97 for perfectionistic concerns in the present study.

Mindfulness. The Mindfulness Attention and Awareness Scale (MAAS; Brown \& Ryan, 2003) was used to assess trait mindfulness that refers to an open or receptive awareness and attention to what is taking place in the present. Sample items include, "I find it difficult to stay focused on what's happening in the present," and "I find myself doing things without paying attention." Composed of 15 items, participants respond to a 6 -point scale $(1=$ almost always, $6=$ almost never), higher scores indicating higher levels of mindfulness. Internal consistency was sound, with .86 among college students (Allan, Bott, \& Suh, 2015). Brown and Ryan (2003) supported the convergent, discriminant, and criterion validity of the MAAS. Internal consistency was .94 in the present study.

Core self-evaluation. The Core Self-Evaluation Scale (CSES; Judge et al., 2003) was used to assess one's appraisal of their worthiness, effectiveness and capability. The CSES is composed of 12 items tapping into self-esteem, self-efficacy, emotional stability, and locus of control, and it is generally suggested to use the items to indicate a uni-dimensional factor (Judge et al., 2003). Sample items include, "I am confident I get the success I deserve in life," and "I determine what will happen in my life." Participants respond to a 5-point scale $(1=$ strongly disagree, 5 = strongly agree), with higher scores indicating greater self-evaluation. Internal consistency ranged from .83 to .87 among college students, and validity was supported (Judge et al., 2003). Internal consistency was .96 for the total score in this study.

Satisfaction with life. The Satisfaction with Life Scale (SWLS; Diener, Emmons, Larsen, \& Griffin, 1985) is a 5-item measure that was used to assess perceived general satisfaction with life as an aspect of subjective wellbeing (Pavot \& Diener, 2008). Participants respond to a 7-point scale ( 1 = strongly disagree, 7 = strongly agree), with higher scores indicating greater levels of life satisfaction. Sample items include, "I am satisfied with my life," and "If I could live my life over, I would change almost nothing." Internal consistency of the measure among college students was .84 (Steger, Frazier, Oishi, \& Kaler, 2006), and convergent validity was supported (Pavot \& Diener, 2008). Internal consistency was .98 in the present study.

Depression. The Center for Epidemiological Studies - Depression (CES-D; Radloff, 1977) was used to assess symptoms of depression. Sample items include, "I thought my life had been a failure" and "I was bothered by things that usually don't bother me." Composed of 20 items, participants responded using a 4 -point scale $(0=$ rarely or none of the time, $3=$ most or all of the time), with higher scores indicating higher levels of depressive symptomatology. Following several recommendations (e.g., Edwards, Cheavens, Heiy, \& Cukrowicz, 2010), 15 items from the original 20 items were used to create a single indicator of depression. Good internal consistency was evidenced (.87) among a large adult sample (Edwards, Cheavens, Heiy, \& Cukrowicz, 2010), and convergent and discriminant validity of the original measure was supported (Radloff, 1977). Internal consistency of 15 items was .95 in the present study.

Anxiety. The Self-Rating Anxiety Scale (SRAS; Zung, 1971) was used to assess symptoms of anxiety. Sample items include, "I get upset easily or feel panicky" and "I feel more nervous and anxious than usual." The scale is composed of 20 items, and participants are asked to respond using a 4-point scale $(1=$ none or a little of time, $4=$ most of all of the time $)$, with higher scores indicating higher levels of anxiety. Olatunji, Deacon, Abramowitz, and Tolin (2006) reported 
adequate internal consistency of .81 among college students, and validity was evidenced (e.g., Tanaka-Matsumi \& Kameoka, 1986). Internal consistency was .99 in the present study.

\section{Results}

This study first tested whether mindfulness and core self-evaluation sequentially mediate the influence of perfectionism on wellbeing. Serial meditation analyses (PROCESS Model 6) were conducted with 10,000 bootstrapped samples (Hayes, 2013). All variables were z-transformed in order to compare effect sizes, but raw score descriptive statistics are reported in Table 2. Table 3 summarizes path coefficients, standard errors, and model summary information of these models.

Table 2. Descriptive statistics (mean, standard deviation, correlation)

\begin{tabular}{|c|c|c|c|c|c|c|c|c|c|}
\hline Variable & Mean & SD & 1 & 2 & 3 & 4 & 5 & 6 & 7 \\
\hline 1. Perfectionistic striving & 40.88 & 6.19 & - & & & & & & \\
\hline 2. Perfectionistic concerns & 48.74 & 15.42 & .08 & - & & & & & \\
\hline 3. Mindfulness & 55.62 & 11.90 & .03 & $-.38^{* *}$ & - & & & & \\
\hline 4. Core self-evaluation & 40.73 & 7.28 & $.16^{* *}$ & $-.66^{* *}$ & $.37^{* *}$ & - & & & \\
\hline 5. Life satisfaction & 24.06 & 6.23 & $.18^{* *}$ & $-.37^{* *}$ & $.19^{* *}$ & $.60^{* *}$ & - & & \\
\hline 6. Depression & 12.62 & 8.39 & -.01 & $.49^{* *}$ & $-.27^{* *}$ & $-.57^{* *}$ & $-.33^{* *}$ & - & \\
\hline 7. Anxiety & 37.58 & 8.85 & -.05 & $.52^{* *}$ & $-.33^{* *}$ & $-.58^{* *}$ & $-.39^{* *}$ & $.67^{* *}$ & - \\
\hline
\end{tabular}

Note. ${ }^{* *} p<.01$.

Table 3. Regression coefficients, standard errors, and model summary of the serial multiple mediator model

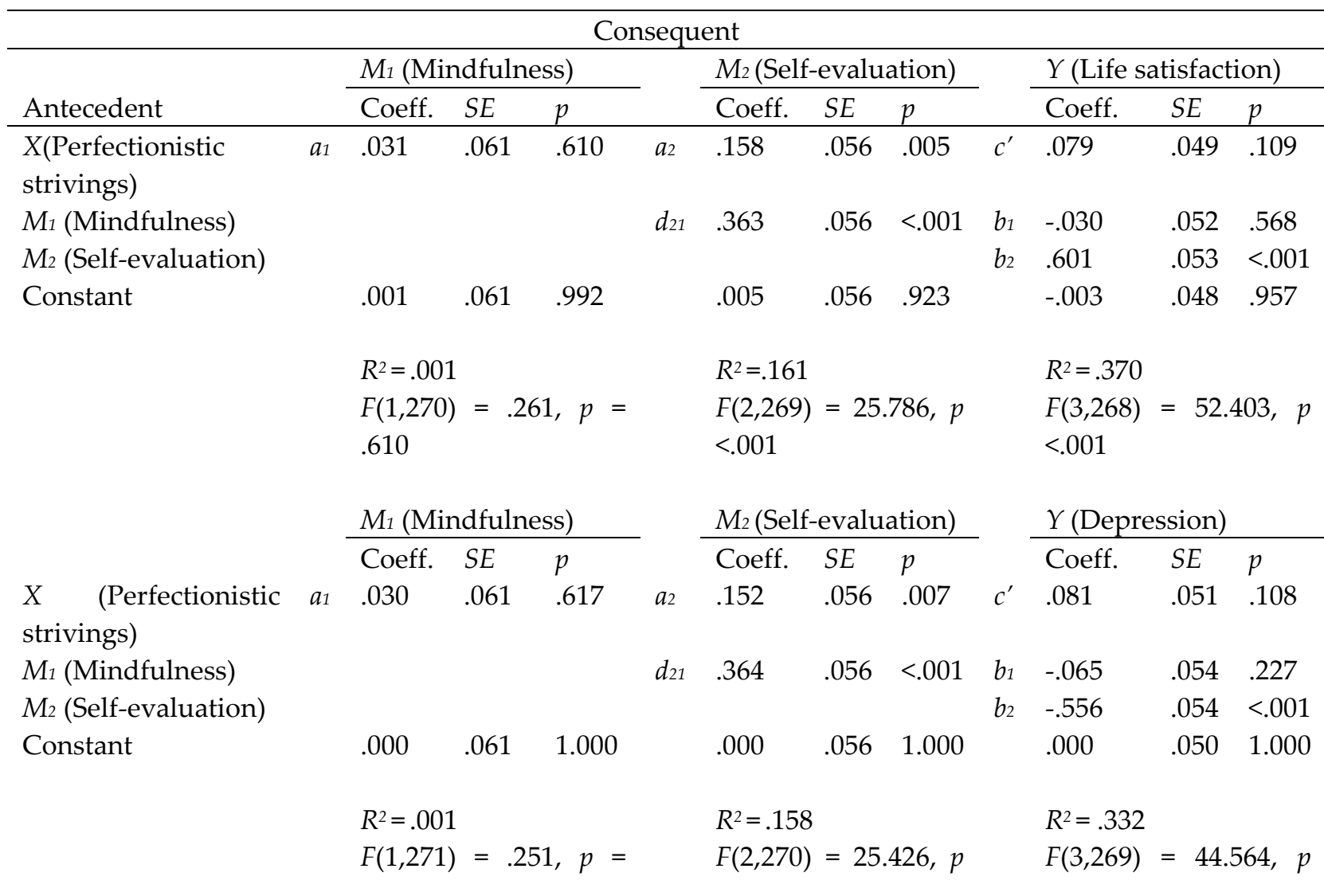


.617

$<.001$

$<.001$

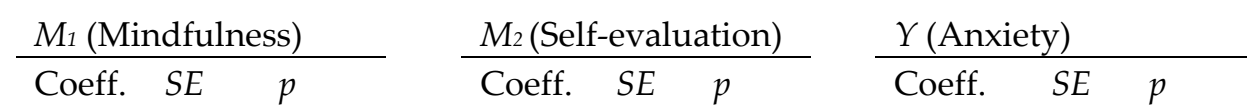

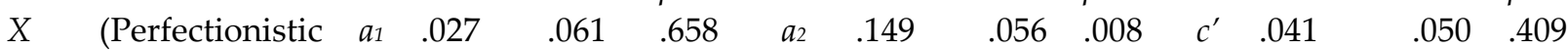

strivings)

$M_{1}$ (Mindfulness)

$\begin{array}{llllllll}d_{21} & .358 & .056 & <.001 & b_{1} & -.136 & .053 & .011\end{array}$

$M_{2}$ (Self-evaluation)

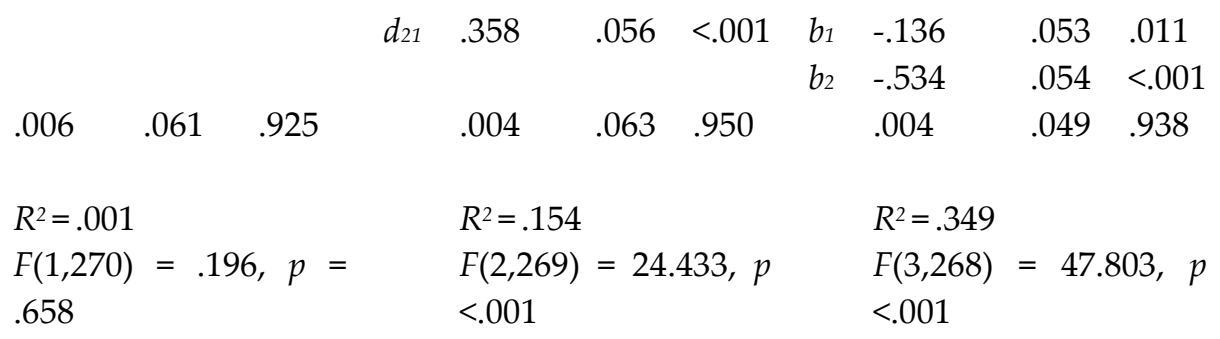

Constant

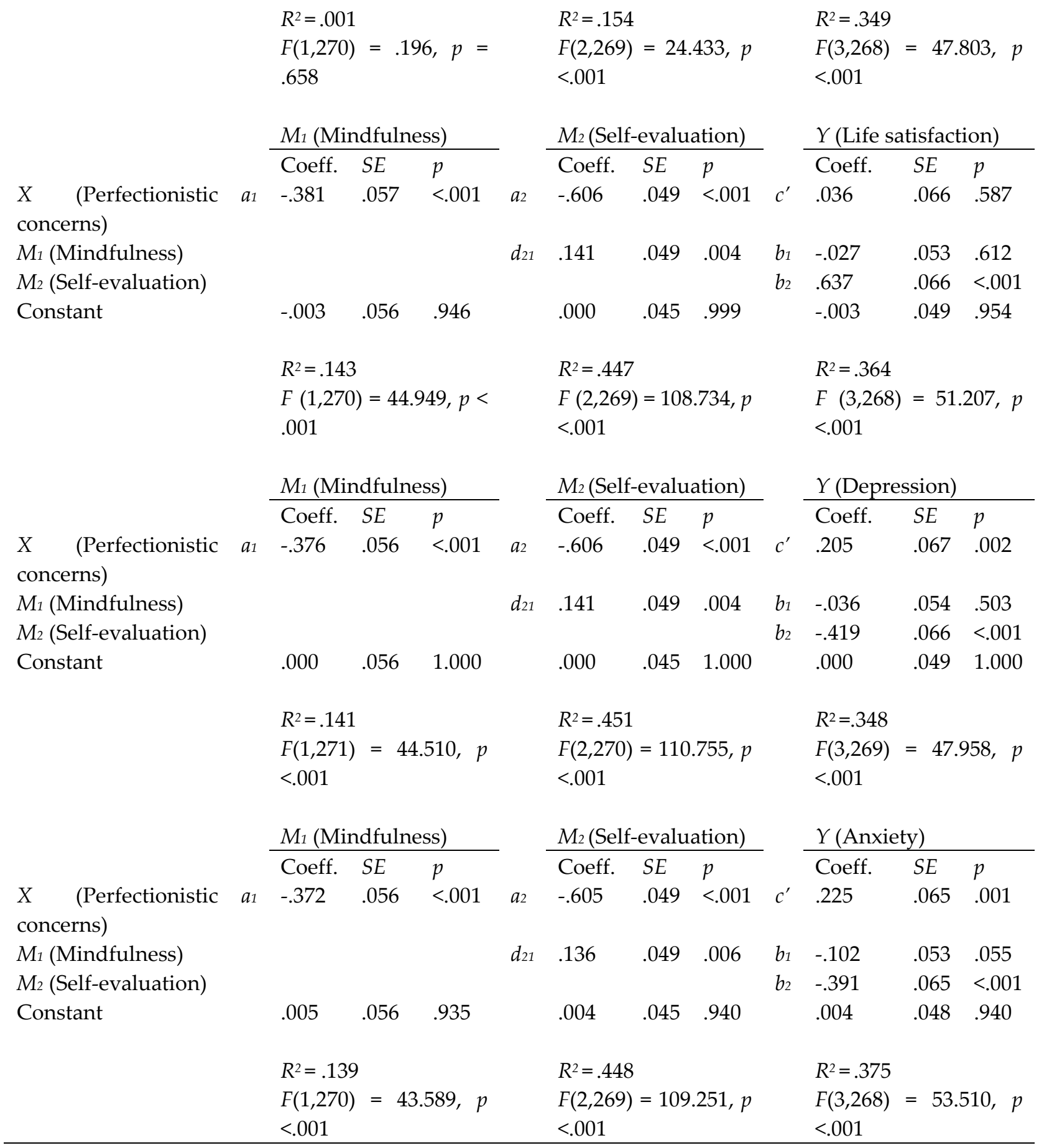




\subsection{Perfectionistic strivings and outcome variables}

The total effect of perfectionistic strivings $(c)$ on life satisfaction was significant $(\beta=.180, t=$ $2.998, p=.003)$, but the total effect, removing the effect of the mediators $\left(c^{\prime}\right)$, was not significant $(\beta=.079, t=1.606, p=.109)$. The total indirect effect that sums all specific indirect effects was significant at a point estimate of $.101(95 \% \mathrm{CI}=.032$ to .173$)$. The specific indirect effect through mindfulness only was not significant $\left(a_{1} b_{1}=-.001 ; 95 \% \mathrm{CI}=-.016\right.$ to .003$)$, but the specific indirect effect through self-evaluation only was significant $\left(a_{2} b_{2}=.095,95 \% \mathrm{CI}=.033\right.$ to .165$)$. The serial multiple mediation model, with the specific indirect effect of perfectionistic strivings on life satisfaction through both mindfulness and self-evaluation, was not significant $\left(a_{1} b_{2} d_{21}=\right.$ $.007,95 \% \mathrm{CI}=-.019$ to .035 ), indicating that perfectionistic strivings do not affect life satisfaction serially through first mindfulness and then through core self-evaluation. See Figure 1 below.

The total effect of perfectionistic strivings $(c)$ on depression was not significant $(\beta=-$ $.011, t=-.180, p=.858)$, and the total effect, removing the effect of the mediators $\left(c^{\prime}\right)$, was not significant $(\beta=.081, t=1.611, p=.108)$. The total indirect effect that sums all specific indirect effects was significant at a point estimate of $-.092(95 \% \mathrm{CI}=-.172$ to -.024$)$. The specific indirect effect through mindfulness only was not significant $\left(a_{1} b_{1}=-.002 ; 95 \% \mathrm{CI}=-.023\right.$ to .005$)$ but the specific indirect effect through self-evaluation only was significant $\left(a_{2} b_{2}=-.084,95 \% \mathrm{CI}=-.156\right.$ to -.028). The serial multiple mediation model, with the specific indirect effect of perfectionistic strivings on depression through both mindfulness and self-evaluation, was not significant $\left(a_{1} b_{2} d_{21}=-.006,95 \% \mathrm{CI}=-.034\right.$ to .015$)$, indicating that perfectionistic strivings do not affect depression serially, through first mindfulness, and then through core self-evaluation. See Figure 2 below.

Results on anxiety appeared similar to that of depression. The total effect of perfectionistic strivings $(c)$ on anxiety was not significant $(\beta=-.047, t=-.778, p=.437)$, and the total effect, removing the effect of the mediators $\left(c^{\prime}\right)$, was not significant $(\beta=.041, t=0.826, p=$ .409). The total indirect effect that sums all specific indirect effects was significant at a point estimate of -.088 (95\% CI $=-.171$ to -.019$)$. The specific indirect effect through mindfulness only was not significant $\left(a_{1} b_{1}=-.004 ; 95 \% \mathrm{CI}=-.026\right.$ to .011$)$, but the specific indirect effect through self-evaluation only was significant $\left(a_{2} b_{2}=-.080,95 \% \mathrm{CI}=-.147\right.$ to -.025$)$. The serial multiple mediation model, with the specific indirect effect of perfectionistic strivings on depression through both mindfulness and self-evaluation, was not significant $\left(a_{1} b_{2} d_{21}=-.005,95 \% \mathrm{CI}=-.032\right.$ to .015), indicating that perfectionistic strivings do not affect anxiety serially, through first mindfulness, and then through core self-evaluation. See Figure 3 below.

\subsection{Perfectionistic concerns and outcome variables}

It was tested whether mindfulness and self-evaluation sequentially mediate the influence of perfectionistic concerns on outcomes $\left(\mathrm{H}_{2 a}, \mathrm{H}_{2 b}, \mathrm{H}_{2 c}\right)$. The total effect of perfectionistic concerns (c) on life satisfaction was significant $(\beta=-.373, t=-6.562, p<.001)$, but the total effect removing the effect of the mediators $\left(c^{\prime}\right)$ was not significant $(\beta=.036, t=0.543, p=.587)$. The total indirect effect that sums all specific indirect effects was significant at a point estimate of $-.409(95 \% \mathrm{CI}=$ -.539 to -.296$)$. The specific indirect effect through mindfulness only was not significant $\left(a_{1} b_{1}=\right.$ $.010 ; 95 \% \mathrm{CI}=-.029$ to .056$)$, but the specific indirect effect through self-evaluation only was 
significant $\left(a_{2} b_{2}=-.385,95 \% \mathrm{CI}=-.516\right.$ to -.279$)$. The serial multiple mediation model, with the specific indirect effect of perfectionistic concerns on life satisfaction through both mindfulness and self-evaluation, was significant $\left(a_{1} b_{2} d_{21}=-.034,95 \% \mathrm{CI}=-.070\right.$ to -.007$)$, indicating that the serial mediation model of perfectionistic concerns predicting life satisfaction sequentially through mindfulness and core self-evaluation was supported. See Figure 4 below.

The total effect of perfectionistic concerns $(c)$ on depression was significant $(\beta=.494, t=$ $9.361, p<.001)$, and the total effect, removing the effect of the mediators $\left(c^{\prime}\right)$, was significant as well $(\beta=.205, t=3.076, p=.002)$. The total indirect effect that sums all specific indirect effects was significant at a point estimate of $.289(95 \% \mathrm{CI}=.186$ to .395$)$. The specific indirect effect through mindfulness only was not significant ( $a_{1} b_{1}=.014 ; 95 \% \mathrm{CI}=-.026$ to .067$)$, but the specific indirect effect through self-evaluation only was significant ( $a_{2} b_{2}=.254,95 \% \mathrm{CI}=.157$ to .353 ). The serial multiple mediation model, with the specific indirect effect of perfectionistic concerns on depression through both mindfulness and self-evaluation, was significant ( $a_{1} b_{2} d_{21}=.022,95 \%$ $\mathrm{CI}=.006$ to .049 ), indicating that the serial mediation model of perfectionistic concerns predicting depression sequentially through mindfulness and core self-evaluation was supported. See Figure 5 below.

The total effect of perfectionistic concerns $(c)$ on anxiety was significant $(\beta=.519, t=$ 9.991, $p<.001)$, and the total effect, removing the effect of the mediators $\left(c^{\prime}\right)$, was significant as well $(\beta=.225, t=3.444, p=.001)$. The total indirect effect that sums all specific indirect effects was significant at a point estimate of $.294(95 \% \mathrm{CI}=.191$ to .409$)$. The specific indirect effect through mindfulness only was not significant ( $a_{1} b_{1}=.038 ; 95 \% \mathrm{CI}=-.002$ to .093$)$, but the specific indirect effect through self-evaluation only was significant ( $a_{2} b_{2}=.237,95 \% \mathrm{CI}=.142$ to .346$)$. The serial multiple mediation model, with the specific indirect effect of perfectionistic concerns on anxiety through both mindfulness and self-evaluation, was significant ( $a_{1} b_{2} d_{21}=.020,95 \% \mathrm{CI}$ $=.004$ to .045), indicating that the serial mediation model of perfectionistic concerns predicting anxiety sequentially through mindfulness and core self-evaluation was supported. See Figure 6 below. 


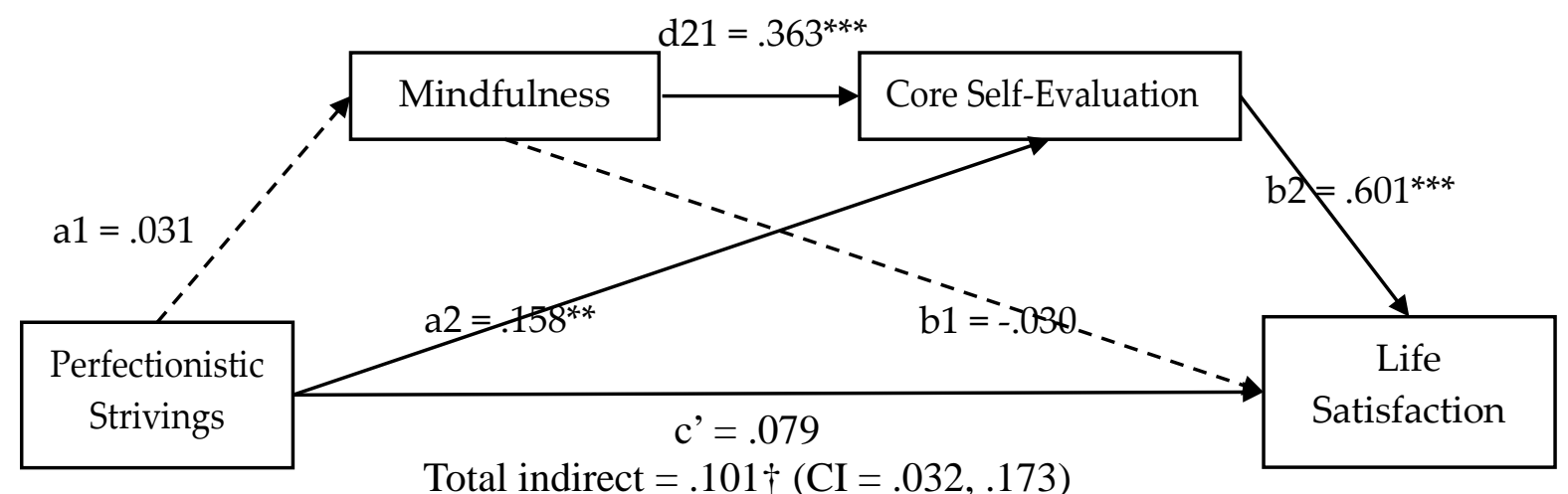

Figure 3. Model 1: Serial multiple mediation model of perfectionistic strivings on life satisfaction, with $\mathrm{M} 1$ as mindfulness and M2 as core self-evaluation $+95 \% \mathrm{CI}$ of the estimate indicates a significant total indirect effect. Note. ${ }^{* * *} p<.001,{ }^{* *} p<.01$. $\rightarrow$ significant path; $-->$ non-significant path.

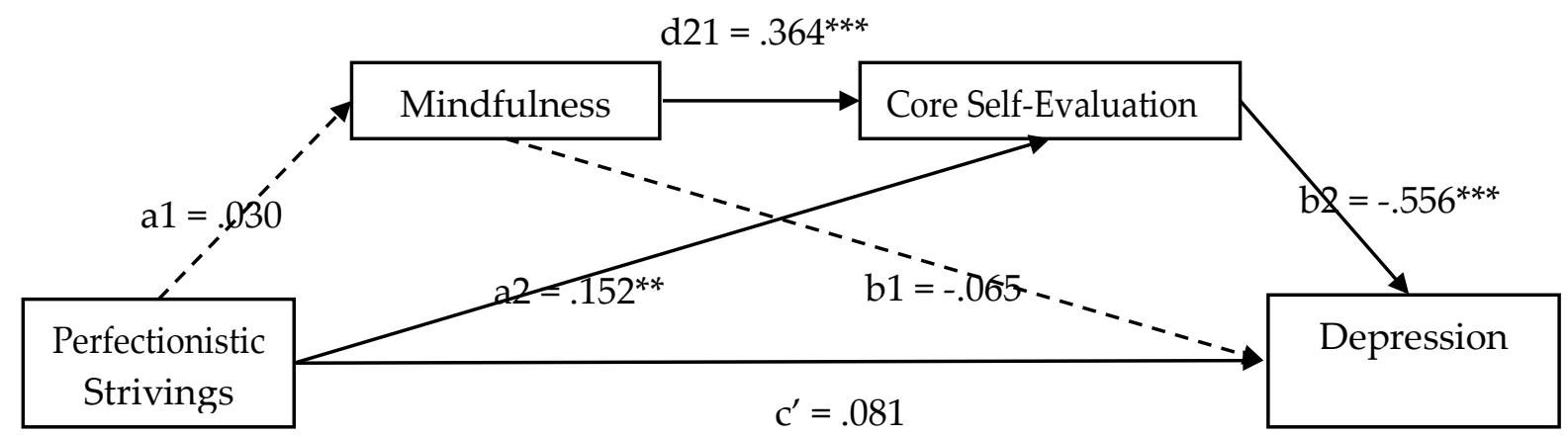

Total indirect $=-.092+(\mathrm{CI}=-.172,-.024)$

Figure 2. Model 2: Serial multiple mediation model of perfectionistic strivings on depression, with M1 as mindfulness and M2 as core self-evaluation $+95 \% \mathrm{CI}$ of the estimate indicates a significant total indirect effect. Note. ${ }^{* * *} p<.001,{ }^{* *} p<.01$. $\rightarrow$ significant path; $-->$ non-significant path.

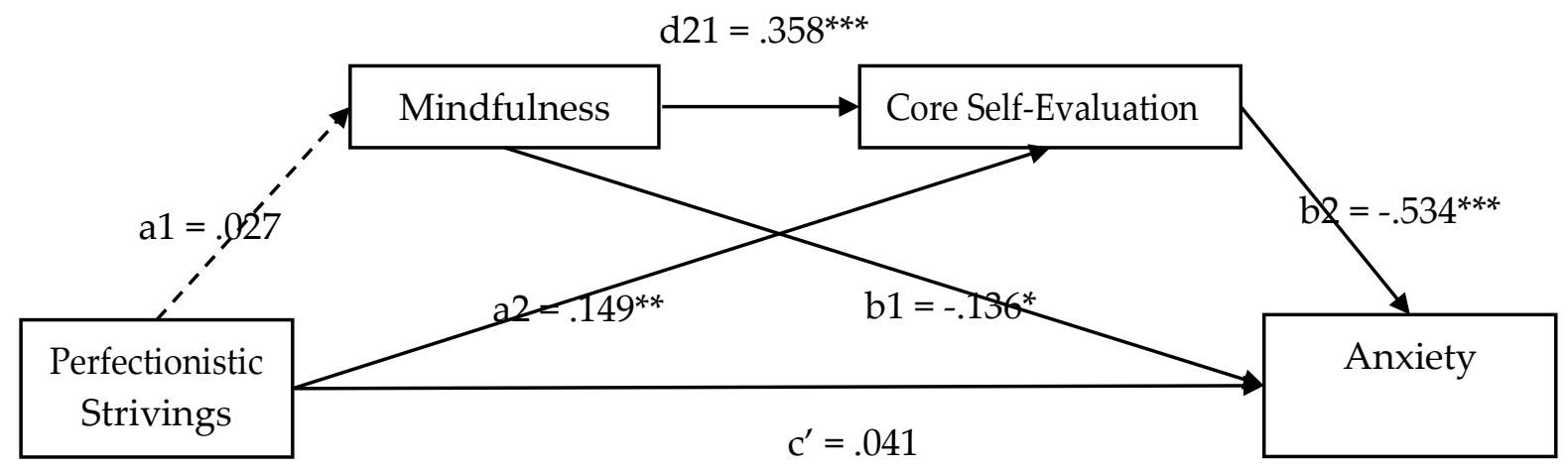

Total indirect $=-.088+(\mathrm{CI}=-.171,-.019)$

Figure 1. Model 3: Serial multiple mediation model of perfectionistic strivings on anxiety, with M1 as mindfulness and M2 as core self-evaluation $+95 \% \mathrm{CI}$ of the estimate indicates a significant total indirect effect.

Note. ${ }^{* * *} p<.001,{ }^{* *} p<.01,{ }^{*} p<.05$. $\rightarrow$ significant path; $-->$ non-significant path. 


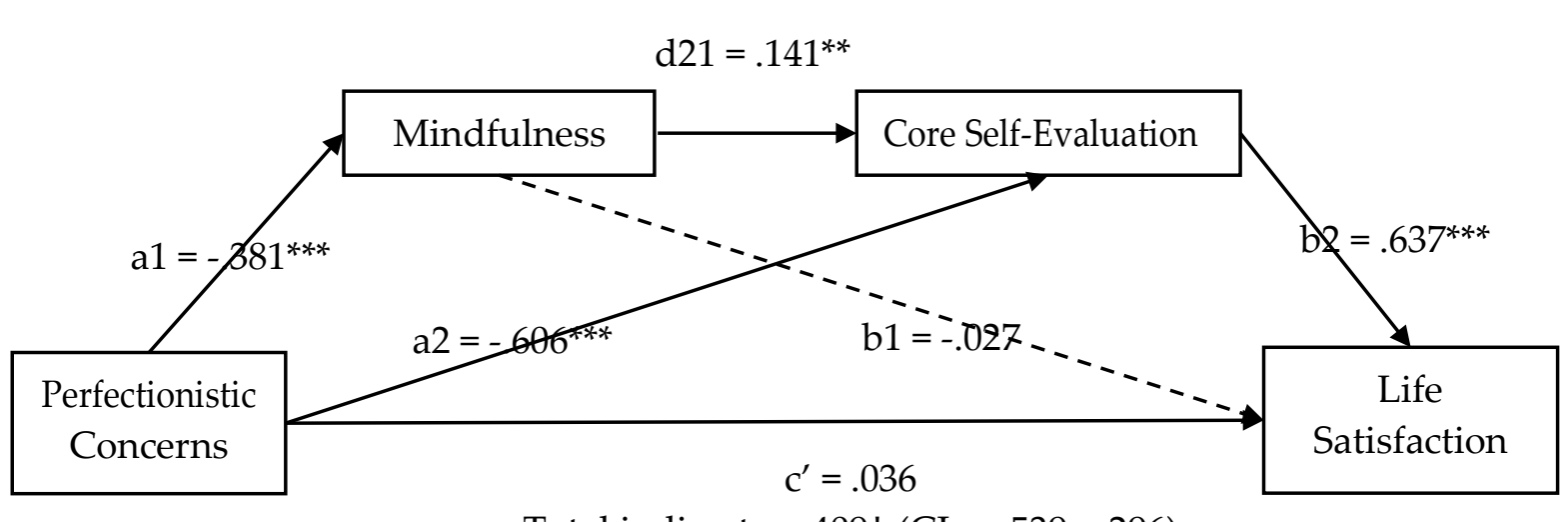

Total indirect $=-.409+(\mathrm{CI}=-.539,-.296)$

Figure 4. Model 4: Serial multiple mediation model of perfectionistic concerns on life satisfaction, with $\mathrm{M} 1$ as mindfulness and M2 as core self-evaluation $+95 \% \mathrm{CI}$ of the estimate indicates a significant total indirect effect.

Note. ${ }^{* *} p<.001,{ }^{* *} p<.01$. $->$ significant path; - - > non-significant path.

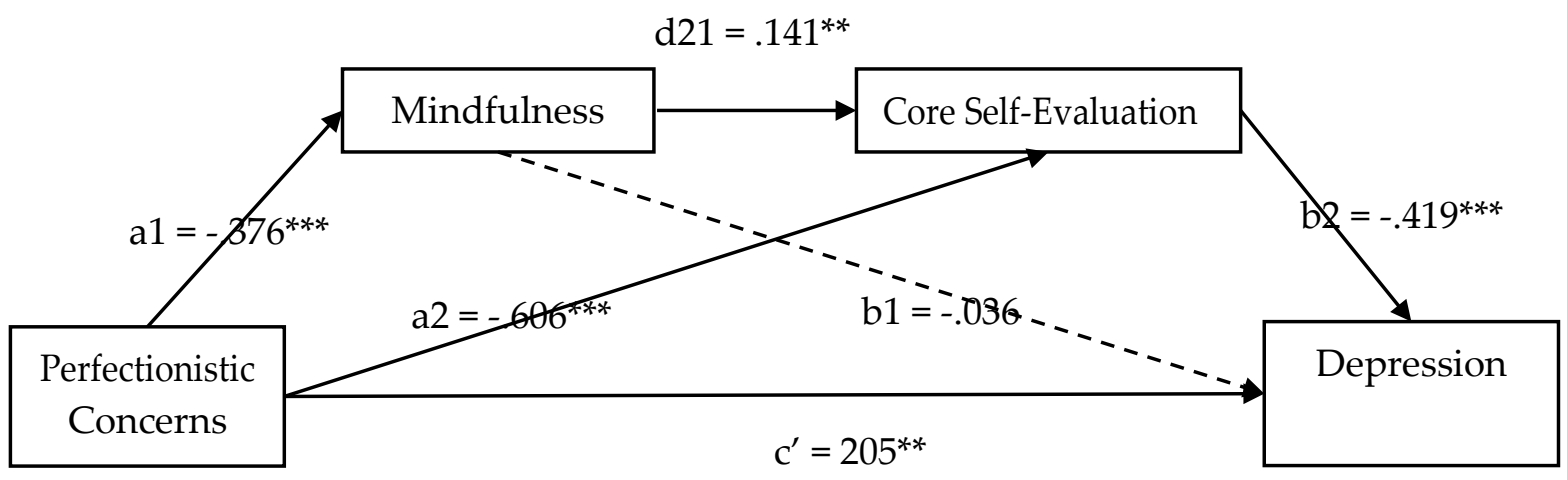

Total indirect $=.289+(\mathrm{CI}=.186, .395)$

Figure 5. Model 5: Serial multiple mediation model of perfectionistic concerns on depression, with M1 as mindfulness and M2 as core self-evaluation $+95 \% \mathrm{CI}$ of the estimate indicates a significant total indirect effect.

Note. ${ }^{* * *} p<.001,{ }^{* *} p<.01$. $\rightarrow$ significant path; - - > non-significant path.

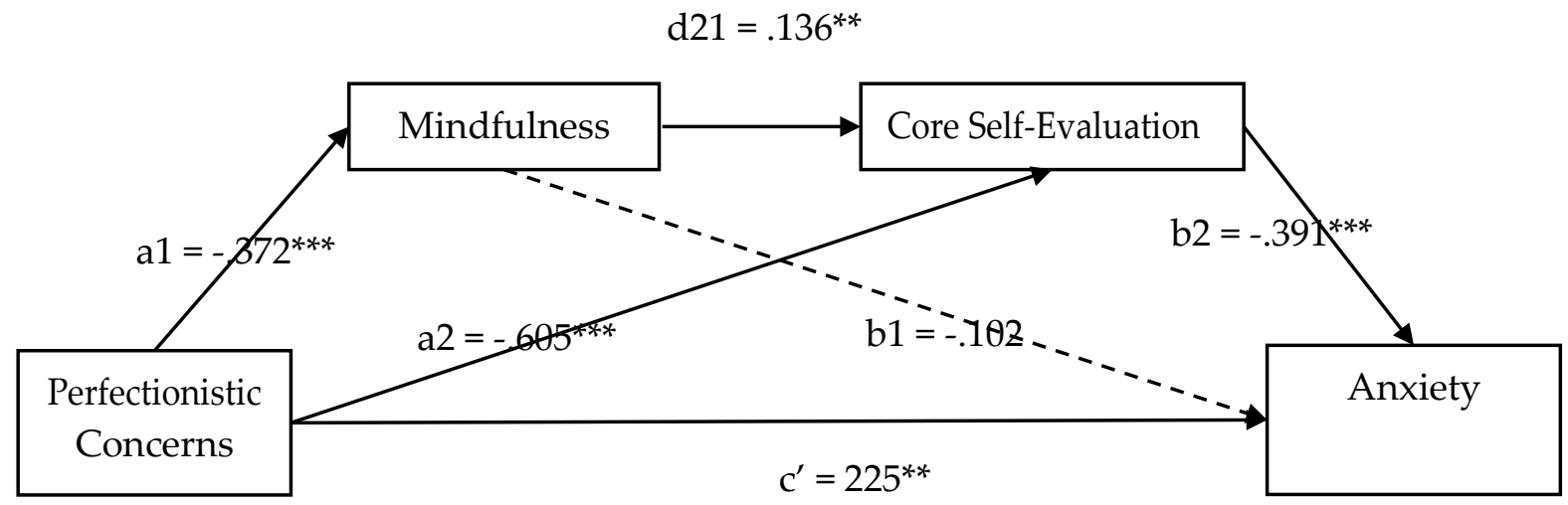

Total indirect $=.294+(\mathrm{CI}=.191, .409)$

Figure 6. Model 6: Serial multiple mediation model of perfectionistic concerns on anxiety, with $\mathrm{M} 1$ as mindfulness and M2 as core self-evaluation $+95 \% \mathrm{CI}$ of the estimate indicates a significant total indirect effect.

Note. ${ }^{* *} p<.001,{ }^{* *} p<.01 .->$ significant path; - - > non-significant path. 


\section{Discussion}

This study examined whether the relation between motivational orientations (perfectionistic strivings, perfectionistic concerns) and wellbeing is sequentially mediated by mindfulness and core self-evaluation. All three hypotheses on perfectionistic strivings $\left(\mathrm{H}_{1 a}, \mathrm{H}_{1 b}\right.$, and $\left.\mathrm{H}_{1 c}\right)$ were not supported, rejecting sequential mediation models with life satisfaction, depression, and anxiety. First, in understanding the total (c) and direct effects $\left(c^{\prime}\right)$, perfectionistic strivings were positively correlated with life satisfaction $(c=.180, p=.003)$, but this relationship was no longer significant once multiple mediators were included in the model $\left(c^{\prime}=.079, p=.109\right)$. Perfectionistic strivings with depression and anxiety were not significantly correlated respectively $(\mathrm{c}=-.011, p=.858 ; \mathrm{c}=-.047, p=.437)$, and even when mediators were included respectively $\left(c^{\prime}=.081, p=.108 ; c^{\prime}=.041, p=.409\right)$. In other words, perfectionistic strivings alone are not a risk factor to depression and anxiety, whereas perfectionistic strivings alone can facilitate experiences of life satisfaction. This result aligns well with the adaptive conceptualization of perfectionistic strivings (Stoeber \& Otto, 2006), and to conceptualizing perfectionistic strivings as reflective of autonomous motivational orientation, given that autonomous motivational orientation is linked to greater wellbeing. Based on SDT, autonomous orientation is an important precedent to psychological health (Ryan \& Deci, 2017).

Regarding specific indirect effects, perfectionistic strivings influenced life satisfaction, depression, and anxiety indirectly through positive appraisal of one's worthiness, effectiveness, and capabilities in the expected directions. In other words, one's striving for excellence grounded in inner needs, values, and goals may guide one to favorably perceive and assess oneself, which subsequently leads to wellbeing and low distress. This finding again suggests that perfectionistic strivings is an "adaptive" characteristic that orients and energizes people to approach and achieve self-set expectations and goals (Stoeber, Damian, \& Madigan, 2018). Interestingly, mindfulness did not mediate the effects perfectionistic strivings had on either core self-evaluation or outcome variables. It is unclear what this finding points at, other than acknowledging that when individuals are driven by autonomous motivational orientation, they are being driven via internalized regulation with clear values and intrinsic motivations, which might already be sufficient to be linked to core self-evaluation and outcomes.

As for perfectionistic concerns, all three hypotheses $\left(\mathrm{H}_{2 a}, \mathrm{H}_{2 b}\right.$, and $\left.\mathrm{H}_{2 c}\right)$ were supported. First, perfectionistic concerns were negatively correlated with life satisfaction, but this relationship was no longer significant once multiple mediators were included. Perfectionistic concerns significantly positively correlated to depression and anxiety both with and without mediators. Second, examination of direct effects of perfectionistic concerns on outcome variables showed that striving for excellence in the presence of self-doubt was associated with low life satisfaction and with high depression and anxiety, even controlling for the effects of mediators. This finding is consistent with propositions arguing perfectionistic concerns as a risk factor to depression and anxiety (Egan, Wade, \& Shafran, 2011).

This result also supports positioning perfectionistic concerns as reflective of controlled motivational orientation from SDT. SDT argues that individuals guided by controlled motivation are sensitive to failure cues and negative feedback, while behaviors are likely driven 
by introjected demands; this culminates in lifestyles or activities that are thwarting basic needs, which then predict "antagonist outcomes" (Deci \& Ryan, 2012). Thus, individuals driven by controlled motivation set high expectations out of fear of failure, while constantly monitoring personal inadequacies. Consequently, this hinders them from meeting basic needs of autonomy and competence, and hence put them at greater risk for poor wellbeing.

Regarding indirect effects, perfectionistic concerns influenced outcome variables sequentially via mindfulness and core self-evaluation. Thus, those with a tendency to be critical and preoccupied with perceived inadequacies have inhibited experiences of paying scant attention to internal and external processes, and those who had a low mindful tendency perceived themselves to be not worthy and capable. Core self-evaluation was positively related to depression and anxiety and inversely related to life satisfaction. Indeed, many studies note that a brooding ruminative responsive style is linked to poor psychological health $\left(\mathrm{O}^{\prime}\right.$ Connor, O'Connor, \& Marshall, 2007; Olson \& Kwon, 2007). Moreover, when one is preoccupied with locating personal inadequacies, paying attention to a full range of thoughts and emotions, even those that are positive attributes and success experiences, is hindered, leaving less margin for favorable self-evaluation. In sum, if motivational orientation is propelled by external demands, rewards, and self-contingencies, and such orientation has been continuously reinforced, one becomes incapable of being attentive and aware of present moment experiences, given that meeting demands and contingencies are of utmost priority. For instance, Shapiro, Carlson, Astin, and Freedman (2006) note that mindfulness is composed of attention, intention, and attitude, and suggest that "intentionally cultivating nonjudgmental attention leads to connection, which leads to self-regulation and ultimately to greater order and health" (p. 380).

This process through which controlled motivation leads to low mindfulness, which then leads to poor core self-evaluation, also may reflect introjected regulation in SDT. Schultz and Ryan (2015) note that introjected regulation is aimed at getting self- and other- contingent approval to avoid guilt, while building self-esteem through ego-enhancement, and that the consequence of introjected regulation is stress and low wellbeing. Thus, controlled motivational orientation in the absence of mindfulness boosts negative self-evaluative emotions (e.g., guilt, shame), which then tarnishes evaluating oneself favorably. The consequence is poor psychological health.

In sum, this study suggests that there are different pathways between motivational orientations and wellbeing that should be considered. Specifically, efforts to build wellbeing among those with perfectionistic strivings can focus on relating the positive effects of perfectionistic strivings to building a "healthy self," as reflected in higher scores in core selfevaluation. On the other hand, deleterious effects of perfectionistic concerns on wellbeing can be attenuated by increasing mindfulness as a way to weaken its path to negatively influencing core self-evaluation and wellbeing.

\section{Limitations}

This study has several limitations. First, this was a cross-sectional study, and hence causality cannot be inferred. Future studies should verify the direction and effects of identified relations. Second, the sample was composed of college students only, limiting the generalizability of 
current findings. Future studies could examine whether similar patterns of results are evidenced in other age groups or non-college attending peers. This is especially relevant, given a recent review by Curran and Hill (2017) that reported a continuous increase in perfectionism levels over the past 26 years among college students, referring to the hyper-competitive nature of the context in which they are embedded. Comparing college students' and non-college attending peers' perfectionism levels can give hints at whether and to what extent the competitive context is a university culture, or a new societal culture. Unfortunately, we could not locate any studies that directly compared perfectionism levels of college students and. noncollege attending peers. Third, the measure that was used to assess mindfulness in the current study does not fully capture the non-judgment, or self-acceptance component, of mindfulness (Bishop et al., 2004). Utilizing measures that reflect both aspects more explicitly would be beneficial (e.g., the Five Facet Mindfulness Questionnaire), which reflects the Eastern-based mindfulness conceptualization (Ivtzan \& Hart, 2016). In particular, in light of suggestions made by Hart, Ivtzan, and Hart (2013), comparing the role of mindfulness in the self-regulation process with two lineages of mindfulness measures (Eastern-based mindfulness to reflect "meditative mindfulness" vs. Western-based to reflect "creative mindfulness") could be the next step of research that can point to the validity of using these two distinct operationalizations of mindfulness, and assessing any similarities or differences of mindfulness relating to self-regulation.

Despite these limitations, this study supports one mechanism through which motivational orientations affect outcomes, and future studies should explore whether this model holds for various samples utilizing other measures that reflect motivational orientations or mindfulness. For instance, given that perfectionistic strivings and perfectionistic concerns are only one possible indicator of motivational orientations, examining how other indicators of motivational orientations relate to mindfulness, core self-evaluation, and outcomes would be beneficial. It might be also useful to explore whether motivational orientations relate differently to mindfulness influencing other wellbeing indicators that reflect eudaimonic wellbeing (e.g., meaning in life).

\section{Author}

\section{Hanna Suh}

University at Buffalo, State University of New York

hannasuh@buffalo.edu

\section{Publishing Timeline}

Received 14 March 2018

Accepted 12 November 2018

Published 3 April 2018

\section{References}

Allan, B. A., Bott, E. M., \& Suh, H. (2015). Connecting mindfulness and meaning in life: Exploring the role of authenticity. Mindfulness, 6(5), 996-1003. https://doi.org/10.1007/s12671-014- 0341-z 
Argus, G., \& Thompson, M. (2007). Perceived social problem solving, perfectionism, and mindful awareness in clinical depression: An exploratory study. Cognitive Therapy and Research, 32(6), 745-757. https://doi.org/10.1007/s10608-006-9102-1

Bishop, S. R., Lau, M., Shapiro, S., Carlson, L., Anderson, N. D., Carmody, J., . . \& Devins, G. (2004). Mindfulness: A proposed operational definition. Clinical Psychology: Science and Practice, 11(3), 230241. https://doi.org/10.1093/clipsy.bph077

Brown, K. W., \& Ryan, R. M. (2003). The benefits of being present: Mindfulness and its role in psychological well-being. Journal of Personality and Social Psychology, 84(4), 822-848. https://doi.org/10.1037/0022-3514.84.4.822

Curran, T., \& Hill, A. P. (2017). Perfectionism is increasing over time: A meta-analysis of birth cohort differences from 1989 to 2016. http://dx.doi.org/10.1037/bul0000138

Deci, E. L., \& Ryan, R. M. (2012). Motivation, personality, and development within embedded social contexts: An overview of self-determination theory. In R. M. Ryan (Ed.), Oxford handbook of human motivation (pp. 85-107). Oxford, UK: Oxford University Press.

Diener, E. D., Emmons, R. A., Larsen, R. J., \& Griffin, S. (1985). The satisfaction with life scale. Journal of Personality Assessment, 49(1), 71-75. http://dx.doi.org/10.1207/s15327752jpa4901_13

Dunkley, D. M., Mandel, T., \& Ma, D. (2014). Perfectionism, neuroticism, and daily stress reactivity and coping effectiveness 6 months and 3 years later. Journal of Counseling Psychology, 61(4), 616-633. http://dx.doi.org/10.1037/cou0000036

Edwards, M. C., Cheavens, J. S., Heiy, J. E., \& Cukrowicz, K. C. (2010). A reexamination of the factor structure of the Center for Epidemiologic Studies Depression Scale: Is a one-factor model plausible? Psychological Assessment, 22(3), 711-715. http://dx.doi.org/10.1037/a0019917

Egan, S. J., Wade, T. D., \& Shafran, R. (2011). Perfectionism as a transdiagnostic process: A clinical review. Clinical Psychology Review, 31(2), 203-212. http://dx.doi.org/10.1016/j.cpr.2010.04.009

Gillet, N., Lafrenière, M. A. K., Vallerand, R. J., Huart, I., \& Fouquereau, E. (2012). The effects of autonomous and controlled regulation of performance-approach goals on well-being: A process model. British Journal of Social Psychology, 53(1), 154-174. https://doi.org/10.1111/bjso.12018

Grzegorek, J. L., Slaney, R. B., Franze, S., \& Rice, K. G. (2004). Self-criticism, dependency, self-esteem, and grade point average satisfaction among clusters of perfectionists and nonperfectionists. Journal of Counseling Psychology, 51(2), 192-200. https://doi.org/10.1111/bjso.1201810.1037/0022-0167.51.2.192

Hart, R., Ivtzan, I., \& Hart, D. (2013). Mind the gap in mindfulness research: A comparative account of the leading schools of thought. Review of General Psychology, 17(4), 453-466. http://dx.doi.org/10.1037/a0035212

Harvey, B., Milyavskaya, M., Hope, N., Powers, T. A., Saffran, M., \& Koestner, R. (2015). Affect variation across days of the week: Influences of perfectionism and academic motivation. Motivation and Emotion, 39(4), 521-530. https://doi.org/10.1007/s11031-015-9480-3

Hayes, A. F. (2013). Introduction to mediation, moderation, and conditional process analysis: A regression-based approach. New York, NY: Guilford Press.

Howard, J. L., Gagné, M., \& Bureau, J. S. (2017). Testing a continuum structure of self-determined motivation: A meta-analysis. Psychological Bulletin, 143(12), 1346-1377. http://dx.doi.org/10.1037/bu10000125

Ivtzan, I., \& Hart, R. (2016). Mindfulness scholarship and interventions: A review. In A. Baltzell (Ed.), Mindfulness and performance (pp. 3-28). New York, NY: Cambridge University Press.

Judge, T. A., Bono, J. E., Erez, A., \& Locke, E. A. (2005). Core self-evaluations and job and life satisfaction: The role of self-concordance and goal attainment. Journal of Applied Psychology, 90(2), 257-268.

Judge, T. A., Erez, A., Bono, J. E., \& Thoresen, C. J. (2003). The core self-evaluations scale: Development of a measure. Personnel Psychology, 56(2), 303-331. https://doi.org/10.1111/j.1744-6570.2003.tb00152.x 
Khoury, B., Lecomte, T., Fortin, G., Masse, M., Therien, P., Bouchard, V., . . \& Hofmann, S. G. (2013). Mindfulness-based therapy: A comprehensive meta-analysis. Clinical Psychology Review, 33(6), 763771. https://doi.org/10.1016/j.cpr.2013.05.005

Kong, F., Wang, X., \& Zhao, J. (2014). Dispositional mindfulness and life satisfaction: The role of core selfevaluations. Personality and Individual Differences, 56, 165-169. https://doi.org/10.1016/j.paid.2013.09.002

Langer, E. J. (1994). Mindfulness and work. In C. Whitmyer (Ed.), Mindfulness and meaningful work: Explorations in right livelihood (pp. 223-230). Berkeley, CA: Parallax Press.

McAdams, D. P., \& Pals, J. L. (2006). A new big five: Fundamental principles for an integrative science of personality. American Psychologist, 61(3), 204-217. https://doi.org/10.1037/0003-066X.61.3.204

Miquelon, P., Vallerand, R. J., Grouzet, F. M. E., \& Cardinal, G. (2005). Perfectionism, academic motivation, and psychological adjustment: An integrative model. Personality and Social Psychology Bulletin, 31, 913-924. https://doi.org/10.1177/01461672044272298

Nix, G. A., Ryan, R. M., Manly, J. B., \& Deci, E. L. (1999). Revitalization through self-regulation: The effects of autonomous and controlled motivation on happiness and vitality. Journal of Experimental Social Psychology, 35(3), 266-284. https://doi.org/10.1006/jesp.1999.1382

O'Connor, D. B., O'Connor, R. C., \& Marshall, R. (2007). Perfectionism and psychological distress: Evidence of the mediating effects of rumination. European Journal of Personality, 21(4), 429-452. https://doi.org/10.1002/per.616

Olatunji, B. O., Deacon, B. J., Abramowitz, J. S., \& Tolin, D. F. (2006). Dimensionality of somatic complaints: Factor structure and psychometric properties of the Self-Rating Anxiety Scale. Journal of Anxiety Disorders, 20(5), 543-561. https://doi.org/10.1016/j.janxdis.2005.08.002

Olesen, M. H. (2011). General causality orientations are distinct from but related to dispositional traits. Personality and Individual Differences, 51(4), 460-465. https://doi.org/10.1016/j.paid.2011.04.015

Olson, M. L., \& Kwon, P. (2007). Brooding perfectionism: Refining the roles of rumination and perfectionism in the etiology of depression. Cognitive Therapy and Research, 32(6), 788-802. https://doi.org/10.1007/s10608-007-9173-7

Pavot, W., \& Diener, E. (2008). The satisfaction with life scale and the emerging construct of life satisfaction. Journal of Positive Psychology, 3(2), 137-152. https://doi.org/10.1080/17439760701756946

Pepping, C. A., O'Donovan, A., \& Davis, P. J. (2013). The positive effects of mindfulness on self-esteem. Journal of Positive Psychology, 8(5), 376-386.

Radloff, L. S. (1977). The CES-D scale: A self-report depression scale for research in the general population. Applied Psychological Measurement, $385-401$. https://doi.org/10.1177/014662167700100306

Rice, K. G., \& Ashby, J. S. (2007). An efficient method for classifying perfectionists. Journal of Counseling Psychology, 54(1), 72-85. https://doi.org/10.1037/0022-0167.54.1.72

Rice, K. G., Ashby, J. S., \& Slaney, R. B. (2007). Perfectionism and the five-factor model of personality. Assessment, 14(4), 385-398. https://doi.org/10.1177/1073191107303217

Ryan, R. M., \& Deci, E. L. (2008). Self-determination theory and the role of basic psychological needs in personality and the organization of behavior. In O. P. John, R. W. Robbins, \& L. A. Pervin (Eds.), Handbook of personality: Theory and research (pp. 654-678). New York, NY: Guilford Press.

Ryan, R. M., \& Deci, E. L. (2017). Self-determination theory: Basic psychological needs in motivation, development, and wellness. New York, NY: Guilford Press.

Sauer, S., Walach, H., \& Kohls, N. (2011). Gray's behavioural inhibition system as a mediator of mindfulness towards well-being. Personality and Individual Differences, 50(4), 506-511. https://doi.org/10.1016/j.paid.2010.11.019 
Schultz, P. P., \& Ryan, R. M. (2015). The "why," "what," and "how" of healthy self-regulation: Mindfulness and well-being from a self-determination theory perspective. In B. Ostafin, M. Robinson, \& B. Meier (Eds.), Handbook of mindfulness and self-regulation (pp. 81-94). Springer, New York, NY.

Schutte, N. S., \& Malouff, J. M. (2011). Emotional intelligence mediates the relationship between mindfulness and subjective well-being. Personality and Individual Differences, 50(7), 1116-1119. https://doi.org/10.1016/j.paid.2011.01.037

Shapiro, S. L., Carlson, L. E., Astin, J. A., \& Freedman, B. (2006). Mechanisms of mindfulness. Journal of Clinical Psychology, 62(3), 373-386. https://doi.org/10.1002/jclp.20237

Short, M. M., \& Mazmanian, D. (2013). Perfectionism and negative repetitive thoughts: Examining a multiple mediator model in relation to mindfulness. Personality and Individual Differences, 55(6), 716721. https://doi.org/10.1016/j.paid.2013.05.026

Slaney, R. B., Rice, K. G., Mobley, M., Trippi, J., \& Ashby, J. S. (2001). The Revised Almost Perfect Scale. Measurement and Evaluation in Counseling and Development, 34(3), 130-145.

Slemp, G. R., Kern, M. L., Patrick, K. J., \& Ryan, R. M. (2018). Leader autonomy support in the workplace: A meta-analytic review. Motivation and Emotion, 42, 1-19. https://doi.org/10.1007/s11031-018-9698-y

Smith, M. M., Sherry, S. B., Chen, S., Saklofske, D. H., Mushquash, C., Flett, G. L., \& Hewitt, P. L. (2017). The perniciousness of perfectionism: A meta-analytic review of the perfectionism-suicide relationship. Journal of Personality, 86(3), 522-542. https://doi.org/10.1111/jopy.12333

Smith, M. M., Sherry, S. B., Rnic, K., Saklofske, D. H., Enns, M. W., \& Gralnick, T. (2016). Are perfectionism dimensions vulnerability factors for depressive symptoms after controlling for neuroticism? A meta-analysis of 10 longitudinal studies. European Journal of Personality, 30, 201-212. https://doi.org/10.1002/per.2053

Steger, M. F., Frazier, P., Oishi, S., \& Kaler, M. (2006). The meaning in life questionnaire: Assessing the presence of and search for meaning in life. Journal of Counseling Psychology, 53(1), 80-93. https://doi.org/10.1037/0022-0167.53.1.80

Stoeber, J., Damian, L. E., \& Madigan, D. J. (2018). Perfectionism: A motivational perspective. In J. Stoeber (Ed.), The psychology of perfectionism: Theory, research, applications (pp. 19-43). London, England: Routledge.

Stoeber, J., Hutchfield, J., \& Wood, K. V. (2008). Perfectionism, self-efficacy, and aspiration level: Differential effects of perfectionistic striving and self-criticism after success and failure. Personality and Individual Differences, 45(4), 323-327. https://doi.org/10.1016/j.paid.2008.04.021

Stoeber, J., \& Otto, K. (2006). Positive conceptions of perfectionism: Approaches, evidence, challenges. Personality and Social Psychology Review, 10(4), 295-319. https://doi.org/10.1207/s15327957pspr1004_2

Tanaka-Matsumi, J., \& Kameoka, V. A. (1986). Reliabilities and concurrent validities of popular selfreport measures of depression, anxiety, and social desirability. Journal of Consulting and Clinical Psychology, 54(3), 328-333. https://doi.org/10.1037/0022-006X.54.3.328

Thompson, B. L., \& Waltz, J. A. (2008). Mindfulness, self-esteem, and unconditional self-acceptance. Journal of Rational-Emotive \& Cognitive-Behavior Therapy, 26(2), 119-126. https://doi.org/10.1007/s10942007-0059-0

Weinstein, N., \& Ryan, R. M. (2011). A self-determination theory approach to understanding stress incursion and responses. Stress and Health, 27, 4-17. https://doi.org/10.1002/smi.1368

Wimberley, T. E., Mintz, L. B., \& Suh, H. (2016). Perfectionism and mindfulness: Effectiveness of a bibliotherapy intervention. Mindfulness, 7(2), 433-444. https://doi.org/10.1007/s12671-015-0460-1

Zung, W. W. (1971). A rating instrument for anxiety disorders. Psychosomatics, 12(6), 371-379. https://doi.org/10.1016/S0033-3182(71)71479-0 